\title{
Bienes digitales personales y sucesión mortis causa: la regulación del testamento digital en el ordenamiento jurídico español
}

\author{
Jorge Luis Ordelin Font* \\ Salette Oro Boff***
}

\begin{abstract}
RESUMEN
Debido a la importancia que adquieren los bienes digitales en nuestra vida es necesario valorar la posibilidad de su disposición mortis causa, sin embargo, mientras algunos bienes digitales pueden ser transmitidos mortis causa otros no lo pueden ser por tener un marcado carácter personal. El presente artículo tiene como objetivo analizar la figura del testamento digital en el ordenamiento jurídico español, a partir de los presupuestos teóricos y normativos del Derecho de Sucesiones y la protección post mortem de los bienes digitales. Para ello se estudian las principales posiciones doctrinales y legislativas que existen en relación con los tipos de instrumentos, dispositivos, su naturaleza jurídica, contenido y alcance, así como las principales obligaciones de los encargados de cumplir dichas manifestaciones.
\end{abstract}

Testamento digital; albacea digital; bienes digitales

\section{Personal digital assets and succession mortis causa: The regulation of the digital will in the Spanish legal system}

\begin{abstract}
Given the importance acquired by digital goods in our lives, it is necessary to assess the possibility of their disposition mortis causa, however, while some digital assets can be transmitted mortis causa, others cannot be because they have a marked personal character. The objective of this
\end{abstract}

* Doctor en Ciencias Jurídicas por el Tribunal Nacional Permanente de Grados Científicos de la República de Cuba. Investigador posdoctoral del Programa Nacional de Posdoctorado PNPD/CAPES, Programa de Posgraduación Stricto Sensu en Derecho de la Faculdade Meridional IMED, Brasil. Correo electrónico: jlordelin@gmail.com

** Doctora en Derecho, Universidad de Vale do Rio dos Sinos, Brasil. Posdoctorada en Derecho, Universidad Federal de Santa Catarina, Brasil. Profesora del Programa de Pos graduación en Derecho, IMED, Brasil. Correo electrónico: salete.oro.boff@gmail.com>

El presente artículo se realiza con el apoyo del Programa Nacional de Posdoctorado PNPD/CAPES, en el marco de las actividades académicas e investigativas del Programa de Posgraduación Stricto Sensu en Derecho de la Faculdade Meridional IMED, Brasil.

Artículo recibido el 14.2.2019 y aceptado para su publicación el 4.9.2019. 
article is to analyze the figure of the digital testament in the Spanish legal system, based on the theoretical and normative assumptions of Succession Law and the post-mortem protection of digital assets. To this end, are studied, the main doctrinal and legislative positions that exist in relation to the types of dispositive instruments, their legal nature, content and scope, as well as the main obligations of those in charge of fulfilling these manifestations.

\section{Digital will; digital executor; digital assets}

\section{INTRODUCCIÓN}

$\mathrm{L}$ a aprobación de la Ley Orgánica de Protección de Datos Personales y garantía de los derechos digitales (en adelante LOPDPDD) en España, ha traído consigo el reconocimiento dentro del ordenamiento jurídico español de los denominados derechos digitales. Sobre los que confluyen figuras, derechos e instituciones de diversa magnitud e importancia y no existe claridad en relación con su naturaleza jurídica, más allá del ámbito en que estos derechos son ejercidos y el derecho al olvido en búsquedas de internet, entre otros ${ }^{1}$.

Una de las principales novedades que trae la legislación española es el derecho al testamento digital, que implica la posibilidad de disponer de estos luego del fallecimiento de su titular. Sobre esta figura existen múltiples interrogantes, no solo desde el plano teórico teniendo en cuenta los propios fundamentos del Derecho de Sucesiones, sino también desde la propia regulación de esta figura en otras legislaciones como son la Ley 10/2017, de 27 de junio, de las voluntades digitales y de modificación de los libros segundo y cuarto del Código Civil de Cataluña (en adelante Ley de voluntades digitales), dentro de la propia España, así como otros países, Francia, con la Ley por una República Digital (en adelante Ley 2016-1321), o la propuesta de unificación de legislación que hace la National Conference of Commissioners on Uniform State Laws en la Revised Uniform Fiduciary Access to Digital Assets Act (en adelante RUFADAA). En correspondencia con ello el presente artículo tiene como objetivo analizar la figura del testamento digital a partir de los presupuestos teóricos y normativos del Derecho de Sucesiones y la protección post mortem de los bienes digitales, con especial referencia en el ordenamiento jurídico español.

\section{LA DISPOSICIÓN POST MORTEM DE LOS BIENES DIGITALES PERSONALES}

El desarrollo de la tecnología y la utilización de esta para realizar actividades de la vida diaria implica la existencia de un conjunto de bienes digitales que conforman el patrimonio digital de una persona. Los bienes o activos digitales, preferimos llamarlos

\footnotetext{
${ }^{1}$ Título X, Ley Orgánica 3, 2018.
} 
bienes, no son más que todo aquello que alguien posee almacenado en un archivo digital, ya se encuentre en un dispositivo determinado o en otro lugar, por medio de un contrato con el propietario, lo que incluye el almacenamiento en la nube ${ }^{2}$.

Dentro de dicha categoría se encuentran un conjunto de bienes, de disímil naturaleza, de carácter digital, que pueden o no poseer un valor económico y estar almacenados de manera local u online. Dentro de ellos pudiéramos mencionar las cuentas online que permiten el acceso a servicios digitales como almacenamiento en la nube, sistemas de pagos, sistemas de comunicación, y contenidos, entre otros. Empero también debemos mencionar bienes digitales que pueden o no encontrarse en estas cuentas como son música o libros en formato digital, mensajes de correo electrónico, datos íntimos, fotos publicadas en una red social, opiniones vertidas en foros o en blogs, videos y escritos almacenados en la nube, entre otros.

Algunos de estos bienes tienen un marcado carácter patrimonial (bitcoins, saldos positivos en Paypal), sin embargo, otros bienes como las fotos, mensajes privados y videos, no tienen este carácter patrimonial y no son susceptibles de valoración económica. Tanto en uno como en otro supuesto existe la interrogante del destino de estos bienes posterior al fallecimiento de su titular. Mientras los primeros son susceptibles de transmisión mortis causa por las tradicionales normas del Derecho de Sucesiones, en los segundos la situación es más polémica, máxime si se tiene en cuenta que para el acceso a los bienes de carácter patrimonial es necesario contar con el acceso a bienes de carácter personal como cuentas y contraseñas que lo permitan.

No existe una solución única para la regulación de la transmisión mortis causa de los bienes digitales. En la actualidad se debate entre la conciliación de los bienes digitales patrimoniales que son susceptibles de transmisión mortis causa como parte de la herencia y el respeto y protección de los bienes digitales de carácter personal que encuentran un ámbito de protección normativa en el concepto de dato personal.

En esta materia no existe un modelo único de disposición. Aun son pocos los ordenamientos jurídicos que reconocen esta posibilidad, al considerar que tras la muerte del titular del dato personal se extinguen todos los posibles derechos sobre este ${ }^{3}$. Sin embargo, ya comienza a entreverse su regulación en algunos ordenamientos jurídicos:

En Francia, por ejemplo, se reconoce que las instrucciones pueden ser generales o específicas. Las primeras se refieren a todos los datos personales del titular, mientras que, las segundas solo contemplan determinados tipos de datos personales que están registrados ante proveedores de servicios particulares. Las diferencias entre uno u otro tipo de instrucción están definidas por la manera que se dispone el ejercicio de los derechos de

\footnotetext{
${ }^{2}$ LEE, 2015, p. 660.

${ }^{3}$ En México, según lo dispuesto en el artículo 53 apartado 1 de la Ley Federal de Protección de Datos Personales, tras la muerte del titular del dato la solicitud de protección de estos es sobreseída. En Brasil la sucesión digital no ha sido objeto de regulación ni en la Ley 12.965, de 23 de abril de 2014, conocida como Marco Civil de la Internet que establece los derechos y garantías de los usuarios de la red, así como tampoco en la Ley 13.709, de 14 de agosto de 2018 que establece el régimen jurídico de protección de datos personales.
} 
conservación, eliminación y la comunicación de los datos posterior a su muerte. Tanto en uno como en otro caso las instrucciones pueden ser revocadas en cualquier momento (art. 40-1. II Ley 78-17) ${ }^{4}$, y su cumplimiento tiene lugar sin perjuicio de las disposiciones aplicables a los registros públicos que contienen datos personales ${ }^{5}$.

La ley de voluntades digitales de Cataluña, además del testamento, el codicilo o las memorias testamentarias reconoció la instrumentación del documento de voluntades digitales, susceptible de inscripción en un registro electrónico de igual nombre. Este documento contiene "las disposiciones establecidas por una persona para que, después de su muerte, el heredero o el albacea universal, en su caso, o la persona designada para ejecutarlas actúe ante los prestadores de servicios digitales con quienes el causante tenga cuentas activas” $^{6}$, y no produce efectos si existen disposiciones de última voluntad ${ }^{7}$.

La magistrada española Roca Trías en el voto particular discrepante que formulara a la Sentencia del Pleno del Tribunal Constitucional español dictada en el recurso de inconstitucionalidad 4751-2017, del pasado 17 de enero de 2019 delimitó la naturaleza jurídica de este instrumento. Al respecto precisó que aun cuando se denominara a este tipo de instrumento testamento digital, en rigor no es tal, no pudiendo ser entendido como un tipo de testamento o un testamento especial, ya que "no contiene una verdadera ordenación de la sucesión, tan siquiera de los materiales o archivos digitales del causante" 8 .

Sin embargo, lo anteriormente señalado no ha sido óbice para que la recientemente adoptada LOPDPDD regule como un derecho digital el testamento digital ${ }^{9}$. La norma si bien resulta novedosa, al menos en el contexto jurídico iberoamericano, al reconocer el derecho de disposición de los datos posterior a la muerte de su titular y el acceso a contenidos gestionados por prestadores de servicios de la sociedad de la información. Pareciendo por momentos regular dos cuestiones diferentes, sin tener en cuenta la especial relación que existe entre ambas. Ello provoca que la regulación realizada no sea la más feliz, y contraste incluso, en algunos aspectos, con la norma autonómica. A diferencia de aquella no precisa si la utilización del término testamento se hace en su sentido tradicional o si incluye otros posibles instrumentos en los que puede constar las voluntades digitales post mortem.

La regulación española difiere también de la propuesta que realiza la RUFADAA para el ordenamiento jurídico norteamericano. Al utilizar el término will incluye al codicilo, al instrumento testamentario que solo designa a un ejecutor, y también al que

\footnotetext{
${ }^{4}$ Art. 63, Ley No 2016-1321, 2016.

${ }^{5}$ Art. 63, Ley No 2016-1321, 2016.

${ }^{6}$ Art. 6 añade un artículo, el 411-10.1, al capítulo I del título I del libro cuarto del Código Civil de Cataluña. Ley 10, 2017.

${ }^{7}$ Art. 6 añade un artículo, el 411-10.3, al capítulo I del título I del libro cuarto del Código Civil de Cataluña. Ley 10, 2017.

${ }^{8}$ Tribunal Constitucional español, 17.01.2019, recurso de inconstitucionalidad $\mathrm{N}^{\circ}$ 4751-2017.

${ }^{9}$ Art. 96. Ley Orgánica 3, 2018.
} 
lo revoca o revisa ${ }^{10}$. También se establece un sistema de prioridad en relación con los instrumentos en virtud de los cuales se puede realizar actos de disposición del activo digital. La persona en vida puede utilizar una herramienta en línea para indicar al proveedor de servicios la persona a quien podrá revelar, divulgar o ser destinatario de alguno o de todos sus activos digitales incluyendo el contenido de las comunicaciones electrónicas. Disposición que podrá modificar o eliminar las veces que quiera ${ }^{11}$.

Este acto dispositivo tiene preeminencia sobre aquellas formas de disposición que utilizan otros instrumentos, como son, el testamento, los poderes, y otra forma de designación de un fiduciario de todo o alguno de los activos digitales ${ }^{12}$. De esta forma se soluciona la existencia de un posible conflicto entre las instrucciones proporcionadas por el usuario de la herramienta en línea, y aquellos otros actos dispositivos patrimoniales post mortem que pudo haber realizado el fallecido utilizando otros medios o instrumentos.

Solo en el supuesto que no se proporcionen dichas instrucciones en los instrumentos anteriormente referidos es que se podrán aplicar los términos de servicio que rigen el acceso y utilización de los servicios en el entorno digital. Si dichos términos no contemplaran el acceso del fiduciario a los activos digitales, se aplican las reglas predeterminadas previstas en la ley. De esta forma queda diseñado un claro sistema de prioridad de tres niveles para determinar la intención del usuario respecto de cualquier activo digital posterior a su fallecimiento o discapacidad.

La semejanza entre los modelos francés, español y estadounidense se halla precisamente en el valor que le conceden a la autonomía de la voluntad, y difieren, precisamente, en la forma en que esta se ejecuta y materializa. Mientras el modelo norteamericano propone una conciliación entre la práctica sucesoria y la protección de la privacidad de los titulares de las bienes digitales posterior a su muerte, el modelo francés se fundamenta en la disposición de los datos personales y su protección post mortem, lo que también pareciera ocurrir en el español, aunque en este último se regula por un lado el tratamiento de los datos de las personas fallecidas y por el otro el acceso a contenidos gestionados por prestadores de servicios de la sociedad de la información sobre personas fallecidas. En este último supuesto existe el riesgo de existencia de diversos instrumentos que contengan voluntades relacionadas con bienes digitales en dependencia de su tipo, personal o no.

Cuando el ejercicio de las facultades concedidas por el ordenamiento jurídico tienen lugar directamente ante el proveedor del servicio, existe el riesgo de que no todos los proveedores cuenten con la herramienta digital necesaria para realizar este acto dispositivo. En este caso es necesario autorizar otros instrumentos para disponer de aquellos activos que se encuentran alojados ante proveedores de servicios que no ofrecen dicha solución.

Además, como afirman Conway y Grattan, la existencia de un conjunto de proveedores de servicios ante quienes hacer efectiva la solicitud de acceso revela otro problema. Los activos digitales pueden ubicarse en diversos servidores a cargo de una variedad de

\footnotetext{
$10 \S 2.27$, RUFADAA, 2015.

11 § 4. a), RUFADAA, 2015.

$12 \S 4$ b), RUFADAA, 2015.
} 
proveedores de servicios que operan mediante compañías globales y que operan bajo la normativa de múltiples jurisdicciones. Ello evidencia la necesidad de que el tema del acceso post mortem de los bienes digitales requiera un enfoque internacional sobre la determinación de la ley aplicable en este tipo de $\operatorname{casos}^{13}$.

Vista esta diversidad de instrumentos en el que es posible disponer de los bienes digitales, luego del fallecimiento de su titular, es necesario preguntarnos si podemos hablar de un testamento digital.

\section{El testamento digital: sentido y alcance}

El testamento en su concepción tradicional, desde el Derecho de Sucesiones, ha sido concebido como la ley de la sucesión, llamada a regular la situación jurídica que se producirá a la muerte de su autor ${ }^{14}$. Como acto jurídico la disposición para después de la muerte del declarante es precisamente la esencia de la disposición mortis causa ${ }^{15}$. En esencia este es el concepto adoptado por el Código Civil español al considerar como tal "El acto por el cual una persona dispone para después de su muerte de todos sus bienes o de parte de ellos se llama testamento"16.

Partiendo de estas concepciones la doctrina se encuentra dividida en la admisión o no del testamento digital. Para ello debe distinguirse entre esta figura y el testamento online. El primero no es más que el instrumento en el que "una persona manifiesta que desea que su patrimonio digital se transfiera o transmita a otra persona o personas que quedarán al cargo del mismo"17, el "documento legal que permite a una persona dar instrucciones acerca de qué hacer con su presencia digital una vez que fallezca" 18 distinto del testamento online que es, según Giner Gandía, aquel que se realiza por medios digitales $^{19}$.

Otros autores consideran improcedente hablar de un testamento digital como figura particular distinto del testamento tradicional. Para Lluch Cerdá, por ejemplo, no existe esta figura, debido a que no es trascendente el formato o ubicación de estos ${ }^{20}$. Cuando el artículo 96 de la LOPDPDD se refiere al derecho al testamento digital y establece las reglas para el acceso a contenidos gestionados por prestadores de servicios de la sociedad de la información respecto de personas fallecidas no está utilizando el término de "testamento" en su sentido tradicional, aun cuando nada obsta para que en los testamentos tradicionales existan disposiciones relacionadas con los bienes digitales.

\footnotetext{
13 Conway y Grattan, 2017, p. 114.

14 Díez-Picazo y Gullón, 2006, p. 443.

15 LACRUZ y SANCHO, 1988, p. 217.

16 Art. 667. Real Decreto, Código Civil, 1889.

17 Márquez, 2016, p. 2.

18 Giner, 2016, p. 57.

19 Giner, 2016, p. 57.

${ }^{20}$ LluCH, 2016, p. 18.
} 
Siguiendo a Jordano Barea, el contenido del testamento puede clasificarse entre declaraciones normales y típicas, instrumentales y accesorias y las declaraciones anómalas, dentro de estas últimas se identifican las típicas, las atípicas y los actos jurídicos mortis causa $^{21}$. Dentro de las disposiciones anómalas pueden encontrarse las relacionadas con el tipo de bienes a los que nos hemos estado refiriendo. Como afirma Álvarez Lata, es innegable "la inclusión en el testamento de disposiciones denominadas anómalas o atípicas, entre las que se encuentran disposiciones de carácter no patrimonial” 22 . Aun cuando el testamento no contenga disposiciones patrimoniales la inclusión de las disposiciones anómalas es posible, ya que como señalan Lacruz Berdejo y Sancho Rebullida, lo que la ley requiere es la forma testamentaria y no la disposición de bienes ${ }^{23}$.

Admitida esta posibilidad es necesario determinar si estas disposiciones son parte del contenido material del testamento o, este es solo un vehículo formal para realizar estas. Dicha disquisición no es una cuestión baladí, si se toma en cuenta que, en dependencia de la posición que se adopte, así será el régimen jurídico aplicable. El primer supuesto implica que estas disposiciones correrán la misma suerte que las relacionadas con la figura del testamento, en especial la revocación, capacidad del testador, vicios del consentimiento, entre otras; mientras que, en el segundo caso, estarían determinadas por el régimen jurídico de este tipo de acto jurídico ${ }^{24}$.

En este sentido Roca Trías, refiriéndose a las voluntades digitales reguladas en la Ley de Cataluña, manifiesta que el hecho de que estas voluntades tengan eficacia posterior a la muerte de la persona no significa que tengan naturaleza testamentaria ${ }^{25}$. Aunque es de importancia precisar que la naturaleza testamentaria del acto sí existe cuando de forma ordenada se quiere transmitir bienes digitales que son susceptibles de transmisión mortis causa.

La inclusión de disposiciones relativas a los activos digitales personales en el testamento no tiene en cuenta la diferencia que existe entre la capacidad para testar y la capacidad para ser titular de bienes digitales. Mientras la primera es común adquirirla con la mayoría de edad o a partir de una edad determinada ${ }^{26}$, la otra varía en dependencia de los términos y condiciones establecidos por los términos y condiciones del servicio brindado, en el caso de algunas redes sociales, por ejemplo, la edad es de 13 años. A nuestro juicio el testamento solo es un instrumento para disponer de este tipo de bienes, mas no es el único. Si se considera que el concepto de testamento digital, tal como lo hace la actual normativa española, se refiere únicamente al testamento entendido en su

${ }^{21}$ Dentro de las típicas el autor menciona el nombramiento de cargos tutelares, la rehabilitación del indigno, dentro de las atípicas las disposiciones sobre derechos de autor y, como actos jurídicos mortis causa menciona el reconocimiento de hijos no matrimoniales. FAUs, 2004, y LACruZ y SANCHO, 1988, p. 220.

22 Álvarez, 2002, p. 114.

${ }^{23}$ LACRUZ y SANCHO, 1988, p. 221.

24 Álvarez, 2002, p. 114.

25 Tribunal Constitucional español, 17.01.2019, recurso de inconstitucionalidad No N $^{\circ}$ 751-2017.

${ }^{26}$ En España la edad para otorgar testamento es de 14 años, según lo dispuesto en el artículo 663 del Código Civil. 
concepción tradicional, se corre el riesgo de que existiendo patrimonio digital la persona no pueda disponer de este por no poseer la testamenti factio activa. En este sentido debemos reconocer que la regulación realizada en la LOPDPDD es confusa.

En la LOPDPDD tampoco es claro la existencia de un orden de prioridad en el que claramente quede expuesto cómo tener en cuenta la voluntad manifestada en el testamento o en otros instrumentos. Por ejemplo, en el caso del fallecimiento de menores la norma establece que las facultades podrán ser ejercitadas también por los representantes legales o, en el marco de sus competencias, por el Ministerio Fiscal, quien podrá actuar de oficio o a instancia de cualquier persona física o jurídica interesada. Mientras que, en el supuesto del fallecimiento de personas con discapacidad, estas facultades también podrán ser ejercidas por quienes hubiesen sido designados para el ejercicio de funciones de apoyo, si estas facultades se entendieran comprendidas en las medidas de apoyo prestadas por el designado ${ }^{27}$.

En el caso de los menores no es claro si el menor en respeto de su capacidad progresiva podría disponer de sus bienes digitales personales conforme al grado de madurez alcanzado y según su voluntad, y en caso de que así sea, si además de la persona designada esta tendría que cumplir la voluntad del menor de conjunto con sus representantes legales, en el supuesto que ambas responsabilidades no recayeran sobre la misma persona. De otro lado, y en relación con el acto dispositivo de los discapacitados, con la promulgación de la LOPDPDD se añade la expresión referida a "si tales facultades se entendieran comprendidas en las medidas de apoyo prestadas por el designado". Lo que es consustancial con las reformas que en materia de discapacidad se prevén en el ordenamiento jurídico español.

El vigente Anteproyecto de Ley de reforma del Código Civil español en materia de personas con discapacidad propone la regulación de "las medidas de apoyo necesarias para que las personas mayores de edad o emancipadas que las precisen para el adecuado ejercicio de su capacidad jurídica puedan desarrollar plenamente su personalidad y desenvolverse jurídicamente en condiciones de igualdad" ${ }^{28}$. Sin embargo, la mayor dificultad en cuanto a la materialización de dicha regulación legal se halla en el hecho de que las medidas de apoyo previstas en el proyecto tienen como limitante que se extinguen tras la muerte del causante discapacitado ${ }^{29}$.

En la normativa española también resulta ambigua la posibilidad de la coexistencia de un testamento que contenga solo disposiciones relacionadas con bienes susceptibles de

27 Art. 3.3. y 96.d), Ley Orgánica 3, 2018.

28 Art. 21 en el que se propone la modificación al Título XI del Código Civil español, art. 248, Anteproyecto de Ley de reforma del Código Civil español en materia de personas con discapacidad, 2018, pp. 247-310.

${ }^{29}$ Aunque el proyecto de reforma del Código Civil no aborda este particular, la Ley de las voluntades digitales sí brinda la posibilidad en el caso de los poderes preventivos. Sin embargo, nada se dice acerca de la posibilidad de que estos puedan ser ejecutado una vez que la persona haya fallecido. Cfr. Art. 1.4 (Modifica el artículo 222-2, con relación a las voluntades digitales en caso de pérdida sobrevenida de capacidad), Ley 10, 2017, y art. 57 del Anteproyecto de Ley de reforma del Código Civil español en materia de personas con discapacidad, 2018, pp. 247-310. 
transmisión mortis causa y, en otro instrumento, disposiciones acerca de bienes digitales no personales. Tampoco existe certeza respecto de qué sucede cuando se ha utilizado el testamento como vehículo para realizar disposiciones digitales y este es revocado por un testamento posterior que nada dice en relación con este particular.

Es importante señalar que la eficacia del acto dispositivo se halla condicionada por la determinación de la persona que ha de cumplir el encargo y la precisión del alcance de este, sobre aquellos actos que pueden o no realizarse con dichos bienes. A continuación, pasaremos a analizar las principales disposiciones.

\section{Personas legitimadas para la disposición de los bienes DIGITALES DE CARÁCTER PERSONAL}

En el instrumento es necesario que se especifique la persona encargada de acceder y gestionar los bienes digitales. Al respecto se discute si nos encontramos en presencia de un mero ejecutor de las voluntades del testador o un albacea. Hay que tener en cuenta que este último no solo ejecuta la voluntad del testador, sino también "vela para que se lleven a la práctica las últimas voluntades"30. Por ello, si bien un albacea puede ejecutar las voluntades digitales no toda persona encargada de acceder y gestionar a estos bienes puede ser considerada albacea. A nuestro juicio para diferenciar uno de otro caso es necesario tener en cuenta cuáles son las instrucciones que han sido ofrecidas por el titular de los activos digitales.

La posición mayoritaria considera que las funciones del albacea digital se ejercen de igual manera que sucede con los bienes no virtuales ${ }^{31}$. El albacea digital no tiene ninguna diferencia con el albacea tradicional a no ser por el tipo de bienes que gestionará. En consecuencia, se le deberá aplicar el régimen legal previsto para este último, en particular lo relacionado con el carácter personalísimo del cargo, su voluntariedad, gratuidad y temporalidad ${ }^{32}$.

Las legislaciones no en todos los casos reconocen expresamente a la persona designada como un albacea digital. En la legislación francesa, se reconoce que en virtud de las directivas puede designarse una persona responsable de su ejecución, quien tiene el derecho de tomar nota de dichas directivas, así como solicitar su implementación a prestadores de servicios que controlan dichos datos (art. 40-1. II Ley 78-17) ${ }^{33}$. La propuesta

30 Albaladejo García, 1990, p. 3.

31 Márquez, 2016, p. 2.

32 Según el Código Civil español el albacea deberá cumplir el encargo en el período de un año si el testador no ha fijado plazo de forma expresa. Este plazo podrá ser prorrogado por un año y si luego de este aún no se ha cumplido con la voluntad del testador el Secretario Judicial o el notario podrán conceder otra prorroga por el tiempo que consideren necesario según las circunstancias del caso. También los herederos y legatarios pueden de muto acuerdo prorrogar el plazo por el tiempo que crean necesario, aunque si el acuerdo es alcanzado solo por la mayoría esta prórroga no podrá exceder del año. Arts. 904, 905, y 906, Real Decreto. Código Civil, 1889.

33 Art. 63, Ley 2016-1321 (el énfasis es nuestro). 
estadounidense habla de la figura del "fiduciario" en sentido amplio, para referirse tanto al representante personal, al sucesor como al agente o fideicomisario ${ }^{34}$. En este caso se considera que la persona tiene autoridad sobre la propiedad del difunto, en especial sobre aquella que contenga un activo digital sobre el cual este último haya ostentado algún tipo de derecho o interés, aunque nunca podrá ser considerado propietario del activo y por tanto no podrá realizar transacciones con este.

En la actual LOPDPDD el uso del término albacea es controvertido. El legislador eliminó el concepto de albacea testamentario que aparecía recogido en el artículo 3 del Proyecto de Ley Orgánica ${ }^{35}$, en el artículo que lo sustituye reconoció la posibilidad de que el encargo pueda ser realizado tanto por una persona natural como por una persona jurídica, sin embargo, al momento de introducir el artículo 96 y regular la figura del testamento digital lo retoma y establece el "albacea testamentario así como aquella persona o institución a la que el fallecido hubiese designado expresamente" 36 .

No son claras las razones que conllevaron al legislador a eliminar el término de un artículo y retomarlo en otro. Una posible explicación sería el establecimiento de un régimen distinto para la gestión de los datos de las personas fallecidas y otro para la figura del testamento digital. Lo que a su vez provoca una distinción entre la figura del albacea testamentario y la persona o institución designada por el fallecido para el ejercicio post mortem del encargo, sea este acerca de los datos personales o de los contenidos gestionados por prestadores de servicios de la sociedad de la información.

No queda claro si pueden coincidir o no dichas figuras en una misma persona o, por el contrario, el albacea pudiera quedar legitimado cuando aquella no fuera designada. En la designación de la persona encargada de cumplir la voluntad del titular de los bienes pueden coincidir múltiples variantes, desde la designación de un tercero encargado de esta gestión, el encargo a los propios herederos, hasta la designación de varias personas según el tipo de bien digital que se trate gestionar, teniendo en cuenta su preparación y conocimiento. También es posible que se nombre un tercero y al propio tiempo exista un albacea encargado de la gestión y administración del resto de los bienes que no son digitales. En este supuesto pudiéramos encontrarnos, según las instrucciones brindadas, en presencia de dos albaceas cuyo objeto de gestión difiere.

Debido a la complejidad de algunos de estos bienes existe la interrogante de si es necesario o no tener conocimientos respecto de tecnología para poder ejecutar el encargo realizado, o si solo con la contratación de especialistas en la materia ya es suficiente. Todo parece indicar que no es necesario, aunque autores como Lluch Cerdá plantean la necesidad de que el albacea comprenda el alcance de su misión, medios que precisa y cómo puede ejecutarla. Para este autor, estos no son más que los recursos técnicos

\footnotetext{
34 \$2.14, RUFADAA, 2015.

${ }^{35}$ Proyecto de Ley Orgánica de Protección de Datos de Carácter Personal, 2017.

${ }^{36}$ Art. 96.1.b), Ley Orgánica 3, 2018.
} 
necesarios para ejecutar las instrucciones y decisiones del causante, los que deben ser provistos de conjunto con recursos legales y financieros ${ }^{37}$.

Uno de los puntos más peliagudos del cumplimiento del encargo por parte de un tercero designado es su relacionamiento con los herederos o legatarios del causante, autores como González Granado plantean que, "la actuación del llamado (por analogía) albacea digital, puede colisionar y debe ceder ante los derechos de los herederos en cuanto se refiera a cualquier relación jurídica transmisible" 38 . Sin embargo, esta afirmación no es del todo cierta ya que la actuación de la persona designada no se sustenta una colisión sino, más bien, en un actuar coordinado con los herederos y legatarios para cumplir lo así dispuesto por el titular de los bienes digitales. Incluso es posible que, en correspondencia con el tipo de bienes, el tercero pueda ejercer por un determinado período la gestión y defensa de los bienes digitales de carácter personal y, al propio tiempo, pueda actuar como administrador de los bienes digitales transmisibles mortis causa, y repartir los frutos de dicha administración entre herederos y legatarios.

Para evitar cualquier tipo de "contradicción” entre los herederos y los encargados de cumplir las voluntades del causante las legislaciones optan por establecer un sistema de prioridad de unos sujetos sobre otros. La ley catalana, por ejemplo, establece que, en defecto de designación, el heredero, el albacea o el administrador de la herencia pueden ejecutar las voluntades digitales o encargar su ejecución a otra persona ${ }^{39}$. La legislación francesa reguló de manera más mesurada dicha posición y reconoce que en ausencia de una designación o, a menos que se indique lo contrario, en el caso de la muerte de la persona designada, los herederos tienen derecho a conocer las directivas y solicitar su implementación a dichos prestadores de servicios (art. 40-1. II Ley 78-17) ${ }^{40}$. Los herederos podrán ejercer los derechos después de la muerte a los efectos y solo en la medida necesaria para organizar y liquidar el patrimonio de los fallecidos, en particular para identificar y obtener información útil para ello, así como también podrán recibir comunicación de bienes digitales o datos similares a memorias familiares que puedan, según la legislación civil, ser transmisible a los herederos (art. 40-1.III Ley 78-17) ${ }^{41}$.

En el ordenamiento jurídico francés los herederos pueden comunicar a los proveedores de servicios la muerte del causante con la finalidad de que cierren sus cuentas de usuario de manera definitiva, así como que se continúen procesando sus datos. En correspondencia con ello podrán solicitar a dichos proveedores una prueba gratuita de ello (art. 40-1.III Ley 78-17) ${ }^{42}$. Los desacuerdos entre los herederos respecto del ejercicio de cualquiera de los derechos reconocidos en la ley específicamente los relacionados con el acceso de sus datos a los efectos de la liquidación del patrimonio y el cierre de las cuentas se resolverán ante el tribunal de distrito competente (art. 40-1.III Ley

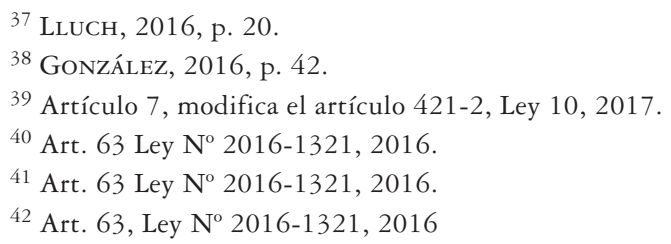


78-17) $)^{43}$. La norma no precisa si es necesario el consentimiento de todos o de algunos de los herederos para el ejercicio de sus derechos reconocidos, ante esta laguna solo será posible aplicar las disposiciones que existen sobre la comunidad hereditaria dentro del ordenamiento jurídico francés. Aun cuando estas normas solo estén referidas a los actos dispositivos de la herencia de bienes materiales.

La sustitución no es clara en la actual regulación española donde el término de "herederos" contemplado en el Proyecto de Ley Orgánica fue modificado por la expresión "personas vinculadas al fallecido por razones familiares o de hecho así como sus herederos", quienes pueden dirigirse al responsable o encargado del tratamiento al objeto de solicitar el acceso a los datos personales de aquella ${ }^{44}$ o acceder a contenidos gestionados por prestadores de servicios de la sociedad de la información e impartirles las instrucciones que estimen oportunas acerca de la utilización, destino o supresión de estos ${ }^{45}$.

La norma en sí es contradictoria porque utiliza los términos de "personas vinculadas al fallecido por razones familiares o de hecho", así como "herederos", sin precisar si los primeros son quienes están debidamente autorizados por el titular de los datos, lo que no es claro, aunque así pudiera colegirse a partir de la interpretación del apartado segundo del precepto cuando señala "las personas o instituciones a las que el fallecido hubiese designado expresamente para ello podrán también solicitar”. Empero, la disposición es extremadamente ambigua en la expresión "personas vinculadas al fallecido por razones familiares o de hecho así como sus herederos" no se corresponden con "personas o instituciones a las que el fallecido hubiese designado expresamente". Mientras que en la primera solo es posible hablar de personas naturales, a menos que el término "de hecho" sea considerado también para las personas jurídicas, en la segunda es claro que tiene lugar ambos tipos de personas. Ello sin tener en cuenta que es posible admitir bajo la primera un sinnúmero de "familiares", y el concepto de "hecho" es más que paradójico. Si entendemos que este último se refiere a las relaciones de pareja su utilización en este precepto es improcedente porque una relación de hecho es también una relación familiar.

\section{INSTRUCCIONES Y OBLIGACIONES: CONTENIDO Y ALCANCE DE LAS DISPOSICIONES}

El primer particular que debe ser resuelto en relación con el alcance de la manifestación es el referido al acceso que podrá tener el encargado. La voluntad debe establecer claramente si este acceso implica el contenido de las comunicaciones electrónicas, o solo el necesario para la rectificación y eliminación de datos o la liquidación del caudal

\footnotetext{
43 Art. 63 Ley N 2016-1321, 2016.

${ }^{44}$ Art. 3.1. Ley Orgánica 3, 2018.

${ }^{45}$ Art. 96.1. a) Ley Orgánica 3, 2018.
} 
hereditario. Como afirma Santos Morón, la regla debe ser la de no presumir la voluntad del fallecido en relación con el acceso al contenido de las comunicaciones electrónicas, así como las personas o entidades con quienes este mantuvo comunicaciones. Solo podrá concederse dicho acceso en el estricto caso que así lo haya manifestado de forma expresa el fallecido, con el fin de garantizar el respeto de lo que fuera su intimidad ${ }^{46}$.

Aun cuando se establezca por la norma tal presunción nada obsta para que en el propio instrumento de disposición se haga expresa alusión a este particular haciendo especial énfasis en aquella información que su titular no desea que se conceda acceso, como pueden ser aquellas que son expresión de una doble identidad virtual de su titular ${ }^{47}$ y que no están directamente relacionadas con la adjudicación de la herencia.

En España, la normativa autonómica considera que si el causante no lo ha establecido, la persona que le corresponde ejecutar las voluntades anticipadas no podrá acceder a los contenidos de sus cuentas y archivos digitales, salvo que obtenga la correspondiente autorización judicial ${ }^{48}$; mientras que la ley orgánica ha optado por la presunción contraria, con la puesta en riesgo y vulnerabilidad del derecho a la privacidad del causante que también merece ser protegido posterior a su fallecimiento. La LOPDPDD trata como excepción la negativa de acceso. Este solo es prohibido cuando la persona fallecida así lo hubiere dispuesto expresamente o lo estableciera la ley, aunque dicha prohibición no podrá afectar el derecho de los herederos a acceder a los datos de carácter patrimonial del causante ${ }^{49}$ o a los contenidos que pudiesen formar parte del caudal relicto ${ }^{50}$.

Las previsiones realizadas en materia de acceso en la RUFADAA son más precisas y certeras. El acceso a los contenidos de las comunicaciones electrónicas del usuario solo podrá ser realizado si el usuario fallecido así lo consintió o un tribunal lo autorizó 51 . El proveedor de servicios solo está obligado a dar a conocer a la persona autorizada por el fallecido el catálogo de las comunicaciones electrónicas enviadas o recibidas por el usuario y los activos digitales que son necesarios para la administración del patrimonio $^{52}$. Este catálogo es distinto del contenido de las comunicaciones electrónicas, cuyo régimen legal se encuentra regulado en la Ley de Privacidad ${ }^{53}$.

La RUFADAA propone que los proveedores no podrán revelar aquellos activos digitales que fueron eliminados por el usuario ${ }^{54}$, se presume, con razón, que el acto de

${ }^{46}$ SANTOS, 2018, pp. 426 y 438.

${ }^{47}$ Es la identidad utilizada en las aplicaciones y cuentas de acceso en Internet. Debe diferenciarse entre identidad virtual y la identidad digital, esta última no es más que la identidad personal en el entorno virtual, mientras es posible tener varias identidades virtuales la identidad digital es única, ya que se construye a partir de nuestra interacción en el ciberespacio. García Herrera, 2017, p. 3.

${ }^{48}$ Art. 6 añade un artículo, el 411-10.6, al capítulo I del título I del libro cuarto del Código Civil de Cataluña. Ley 10, 2017.

49 Art. 3.1. Ley Orgánica 3, 2018.

50 Art. 96.1. a) Ley Orgánica 3, 2018.

$51 \S 7$, RUFADAA, 2015.

$52 \S 8$, RUFADAA, 2015.

53 National Conference of Commissioners on Uniform State Laws, 2015, p. 15.

54 \& 6 c) RUFADAA, 2015. 
eliminación de un activo digital es indicativo de que el fallecido no tenía intención de que existiera un acceso por parte de terceros a este, ya fuera el fiduciario o sus herederos. Asimismo, se precisa que el acceso no implica además de los activos digitales que se encuentran en poder de un determinado proveedor de servicios también, aquellos que se encuentren en los bienes tangibles del difunto, como son las computadoras portátiles, teléfonos inteligentes o medios de almacenamiento, entre otros.

Establecido el acceso a los activos digitales es imprescindible determinar el contenido de las acciones que se pueden desarrollar. Según la ley catalana, en virtud de estas voluntades digitales las personas pueden ordenar las acciones que consideren más adecuadas para facilitar, tras su muerte, la extinción de su personalidad en los entornos digitales, o la perpetuación de la memoria con la conservación de los elementos que se determinen, así como cualquier otra solución que el causante pudiera considerar pertinente en el ejercicio de la libertad civil que le corresponde en vida ${ }^{55}$. La norma concretamente reconoce la posibilidad de: a) comunicar a los prestadores de servicios digitales la defunción del causante. b) solicitar a los prestadores de servicios digitales que se cancelen sus cuentas activas. c) solicitar a los prestadores de servicios digitales que ejecuten las cláusulas contractuales o que se activen las políticas establecidas para los casos de defunción de los titulares de cuentas activas y, si procede, que le entreguen una copia de los archivos digitales que estén en sus servidores ${ }^{56}$.

Para Roca Trías se trata de "la realización de actividades muy concretas que están directamente relacionadas con el ejercicio de derechos personalísimos de carácter no patrimonial, por tanto, no transmisibles mortis causa (...)"57. La ley orgánica no es tan exhaustiva en su regulación como la normativa autonómica, aunque considera que las personas legitimadas por el usuario podrán decidir acerca del mantenimiento o eliminación de los perfiles personales de personas fallecidas en redes sociales o servicios equivalentes, a menos que el fallecido hubiera decidido otra cosa, en cuyo caso se estará a dichas instrucciones ${ }^{58}$.

Tanto en uno como en otro supuesto debe entenderse que estas normas jurídicas no establecen un régimen taxativo de posibles acciones a realizar por parte del encargado. Según las circunstancias de cada supuesto y las instrucciones emitidas por el titular podrán o no realizarse determinadas actividades para la ejecución del encargo. Ambas condiciones deberán ser tenidas en cuenta para interpretar el alcance de la voluntad del fallecido.

55 Preámbulo de la Ley 10, 2017.

56 Art. 6 añade un artículo, el 411-10.2, al capítulo I del título I del libro cuarto del Código Civil de Cataluña. Ley 10, 2017.

57 Tribunal Constitucional español, 17.01.2019, recurso de inconstitucionalidad, No 4751-2017.

58 Art. 96. 2, Ley Orgánica 3/2018. 


\section{Especiales previsiones para la adopción de las instrucciones}

Existen múltiples barreras que deben enfrentarse al momento de redactar las disposiciones relativas a los bienes digitales, al menos en la forma que tradicionalmente se redactan este tipo de cláusulas en los instrumentos de última voluntad, porque hay que tener especial cuidado en relación con la forma en la que queden redactadas dichas disposiciones con el fin de impedir posteriormente que se enerve la ejecución de la voluntad testamentaria.

La primera dificultad que surge está relacionada con la delimitación dentro del testamento del patrimonio digital y su distinción del resto de los bienes. Las disposiciones relativas a bienes de índole digital no son iguales que las del resto de los bienes materiales.

Las instrucciones y disposiciones deben diferenciarse según el tipo de bien digital de que se trate, no solo para garantizar el correspondiente acceso a los mismos, sino también, teniendo en cuenta que no existen normas claras para la valuación de algunos de estos. Cuando dichos bienes son integrados a la masa hereditaria deberán ser objeto de operaciones conexas a la partición hereditaria como son la liquidación de la comunidad matrimonial de bienes y la colación. Por ejemplo, una cuenta de Bitcoin puede tener un valor distinto entre el momento de la aceptación de la herencia y su adjudicación. Ello abre una interrogante acerca de la posibilidad de aceptar la condición de heredero o legatario de bienes digitales sin tener en cuenta el valor de los bienes, o "a ciegas" como afirma Lluch Cerdá59.

Asimismo, en el supuesto que el testador haya declarado las cuentas que posee y sus respectivas contraseñas es necesario la introducción de una cláusula especial que prohíba la obtención de copias de claves de acceso a cualquier persona que no sea el encargado de gestionarlas ${ }^{60}$. En consecuencia, las personas legitimadas a obtener copias del testamento podrán o no ver limitado el acceso a dichas copias en dependencia de lo dispuesto por el testador.

El número de cuentas y bienes puede ir en aumento o desaparecer entre el período que se otorga el testamento y la fecha en que la persona fallece, ello sin contar que estas cuentas están protegidas por contraseñas que suelen cambiarse periódicamente. De esta forma resulta improcedente que se realice una enumeración taxativa de las cuentas y contraseñas en un testamento. Aunque para autores como Lluch Cerdá esto no es un problema, todo lo contrario, es algo muy sencillo de resolver, ya que solo es necesario, a juicio del autor, una persona de confianza suficiente para compartir estos datos de acceso $^{61}$.

Sin dudas es una interesante y fácil posición, sin embargo, deberíamos tener en cuenta si ello es lo que se pretende con esta institución, para generar una verdadera garantía

\footnotetext{
59 LLUCH, 2016, p. 19.

60 GONZÁlez, 2016, p. 42.

${ }^{61}$ LluCH, 2016, p. 18.
} 
de que el encargo posterior a la muerte del titular de dichos bienes será debidamente cumplido. Nada obsta para que esta solución pueda ser llevada a cabo, empero existen reticencias en relación con su seguridad. Vale la pena preguntarnos cuántas personas confiarán sus datos en vida sabiendo que existe un riesgo de que la persona pueda tener acceso a ello, máxime si se tiene en cuenta que los cambios de contraseñas se realizan para surtir efectos desde el mismo momento en que se realizan y no a futuro, y nadie tiene certeza acerca de la fecha de su muerte. La solución propuesta podría tipificar un supuesto de suplantación de identidad sino se comunica al proveedor de servicios el fallecimiento del titular de las cuentas. Precisamente la garantía que ofrece el nombramiento de un tercero para que gestione los bienes digitales posterior al fallecimiento de su titular es evitar el robo de su identidad.

Otro aspecto importante de tener en cuenta cuando se adoptan las instrucciones dentro de este tipo de acto es cuando nos encontramos en presencia del testamento digital inverso, entendiendo por tal aquel acto dispositivo en el que se obliga a la persona encargada a borrar todo el contenido del patrimonio digital que poseía en vida el fallecido $^{62}$. En este caso la obligación de la persona designada es precisamente garantizar y velar porque los proveedores de servicios cumplan con la voluntad del causante, es decir, la eliminación de los archivos. Esta facultad tiene como principal límite el hecho de que dicha eliminación no puede devenir en impedimento para el ejercicio del derecho de terceros a la liquidación del caudal hereditario.

También se propone que una empresa gestora del acervo digital quede a cargo de toda la información posible sobre cuentas, correos electrónicos, datos de acceso, mientras que en el testamento o en el instrumento queden establecidas las instrucciones respecto de qué hacer con este tipo de bienes y quién o quiénes estarían a cargo de dicha gestión, así como del correspondiente acceso ${ }^{63}$. Esta solución resulta interesante, aunque también controvertida, en particular si se tiene en cuenta que estaríamos en presencia de un contrato con un proveedor de servicios que tendría efectos jurídicos posterior a la muerte de una de las partes. Por ello sería prudente no solo disponer que la empresa se encargara directamente de la gestión de estos bienes, sino también nombrar un tercero encargado de velar que la empresa cumpla con dicho encargo, al propio tiempo que deduzca del acervo hereditario los correspondientes pagos que este servicio arrojaría ${ }^{64}$.

Llopis Benlloch sugiere que unido al otorgamiento del testamento se contrate un servicio de depósito de archivos o de gestión de patrimonio digital, o que se contacte a un notario que tenga conocimiento de este tipo de disposiciones ${ }^{65}$. En este caso el notario también interviene a los efectos de autorizar la correspondiente acta de depósito para

${ }^{62}$ Márquez, 2016, p. 2.

63 Domínguez, 2016, p. 62.

${ }^{64}$ Esta posibilidad queda establecida en la normativa autonómica catalana en la que se establece que, si el causante no lo ha establecido de otro modo, los gastos originados por la ejecución de las voluntades digitales corren a cargo del activo hereditario. Vid. Art. 6 añade un artículo, el 411-10.7, al capítulo I del título I del libro cuarto del Código Civil de Cataluña, Ley 10, 2017.

${ }^{65}$ LlOpis, 2016, p. 47. 
dar fe de la existencia del acto de depósito al propio tiempo que comunica su existencia al Registro General de Actos de Última Voluntad ${ }^{66}$.

Como se colige, son innumerables las posibles instrucciones emitidas como voluntades digitales posterior al fallecimiento. Sin embargo, consideramos que, además de estas, es necesario que las leyes establezcan con precisión la naturaleza, extensión y limitación de la autoridad de la persona designada para ejecutar dichas voluntades. La ley debe actuar en sustitución o como complemento de las disposiciones realizadas por el titular del bien digital.

\section{Las obligaciones de la persona designada para ejecutar la voluntad del titular}

Con excepción de la propuesta realizada por RUFADAA las disposiciones normativas consultadas no hacen referencia a los deberes y obligaciones del encargado de cumplir con las disposiciones del titular de los bienes digitales. Por ello es necesario acudir a la figura del albacea como ya apuntábamos. Sin embargo, a nuestro juicio ello no es suficiente para delimitar con claridad el ámbito de actuación del encargado, ya que además de las necesarias instrucciones es necesario un mínimo de funciones que permitan determinar el régimen de responsabilidad de este en el supuesto de un incumplimiento parcial o total de la voluntad del titular de los activos digitales.

Según Lee, refiriéndose a esta figura en Estados Unidos, el régimen de acceso del fiduciario se sustenta en el concepto de neutralidad de los medios o activos, que implica que si el fiduciario, según la ley vigente, tiene acceso a un activo tangible perteneciente al difunto, también debe tener acceso similar al activo digital, aun cuando este se encuentre en poder de un proveedor de servicios de internet ${ }^{67}$. En la gestión de los activos digitales el fiduciario tiene las mismas obligaciones legales que aquellas que le son impuestas a un fiduciario encargado de administrar bienes materiales, en especial, el deber de cuidado, el deber de lealtad y el deber de confidencialidad. Siendo responsable ante el incumplimiento de cualquiera de estos deberes.

Al ejercer sus responsabilidades, el fiduciario está sujeto a las mismas limitaciones que el usuario en general, al igual que este puede impugnar las disposiciones de un acuerdo de términos de servicio y solicitar la cancelación de una cuenta, siempre y cuando ello no viole o impida el ejercicio de sus deberes ${ }^{68}$. También se encuentra sujeto a los términos aplicables al servicio, excepto en la medida en que lo dispuesto en dichos términos de servicio quede anulado por estar en contra de lo establecido en relación con los instrumentos que pueden ser utilizados para realizar el acto dispositivo. Asimismo podrá identificar los activos que tienen un valor real o sentimental, honrando los deseos del difunto sobre quienes pueden o no tener acceso a dichos activos ${ }^{69}$.

\footnotetext{
${ }^{66}$ Salamanca, 2016, p. 37.

${ }^{67}$ LeE, 2015, p. 656.

68 § $15 \mathrm{~g})$, RUFADAA, 2015.

${ }^{69}$ LEE, 2015, p. 662 y 663.
} 
El fiduciario también está obligado a cumplir con los deberes impuesto por las funciones de su cargo y a la aplicación de otras leyes como son las de Derechos de autor ${ }^{70}$. Esto es polémico sobre todo en aquellos casos en que el usuario ha obtenido el archivo digital de manera fraudulenta o ilícita.

Pese a que las disposiciones de la RUFADAA constituyen un modelo de los derechos y obligaciones de quienes tienen el encargo de cumplir la voluntad del titular de los bienes digitales, la norma no ha estado exenta de críticas. En este sentido Lee considera que los derechos del fiduciario deben ser definidos desde una perspectiva de control y no solo desde el acceso, como en su opinión se ha realizado. Para este autor es necesario delinear claramente los poderes del fiduciario en este ámbito para que, a su vez, pueda ejecutar sus deberes. En su criterio el hecho de que el fiduciario pueda hacer lo mismo que el titular de la cuenta es un concepto demasiado amplio que está limitado por las propias obligaciones de los fiduciarios, especialmente en materia de autorización y consentimiento ${ }^{71}$.

Como ya hemos afirmado los deberes y obligaciones del encargado no son objeto de regulación en los ordenamientos jurídicos de tradición romano-francés que hemos analizado. A nuestro juicio esta es una tarea pendiente. Aun cuando puede acudirse a las regulaciones que sobre la figura del albacea se realizan en las tradicionales normas sucesorias, los adelantos tecnológicos y las particularidades de los bienes digitales precisan que así sea. El encargado de cumplir las últimas voluntades digitales no es un mero ejecutor de estas, también debe velar por el respeto de la privacidad del titular de los bienes y defender sus intereses ante los prestadores de servicios. Con el establecimiento mínimo de obligaciones y facultades del encargado se garantiza la efectividad del encargo ante los prestadores del servicio y el cumplimiento de la voluntad del titular.

\section{CONCLUSiOnes}

A partir de lo analizado podemos concluir que el derecho al testamento digital consagrado en el artículo 96 de LOPDPDD no puede ser entendido como la figura del testamento en su concepción tradicional, sino la posibilidad de disponer de bienes digitales para luego del fallecimiento de su titular. La norma no establece una distinción en relación con el tipo de bien digital, personal o no, sin embargo, tampoco es claro en relación con la conciliación de los instrumentos que pueden ser utilizados para disponer entre uno u otro tipo de bien. La ley debe establecer de manera clara un orden de prioridad de estos instrumentos y su relación con el resto de las disposiciones sobre otros bienes digitales. El testamento entendido en su concepción tradicional solo es un mero vehículo para la realización de estas.

\footnotetext{
$70 \S 15$ b. IV. RUFADAA, 2015.

${ }^{71}$ LEE, 2015, p. 697.
} 
Pese a las críticas que pudieran realizarse a la norma esta constituye un importante avance en la materia en los ordenamientos jurídicos que pertenecen al sistema romano francés. Toma como base la autonomía de la voluntad necesario para garantizar que el titular de los bienes digitales pueda disponer de estos para luego de su fallecimiento.

La eficacia del acto dispositivo se halla condicionada por la determinación del régimen de acceso y alcance de las facultades del encargado. Bajo el respeto de la autonomía de la voluntad en estos instrumentos deben constar de manera clara y precisa las principales instrucciones que este debe cumplir para la ejecución del encargo, ello incluye al menos: a) la determinación de la o las personas que podrán tener acceso a estos bienes incluyendo aquellos de carácter personal, b) instrucciones específicas sobre aquellos actos que pueden o no realizarse con dichos bienes, c) la posibilidad de dirigirse directamente a los proveedores de servicios, entre otros.

La ley debe prever un mínimo de facultades y obligaciones en el supuesto de que el titular de los bienes digitales no haya realizado dicha determinación y solo se haya limitado a realizar el nombramiento de o de los encargados. Cualquier propuesta que se haga al respecto debe partir del reconocimiento de que el acceso al contenido de carácter personal del titular solo será posible cuando así lo haya dispuesto el titular. Asimismo, debe distinguirse entre aquel acceso que es necesario para realizar la adjudicación de los bienes digitales con contenido patrimonial y el acceso a los bienes de carácter personal, estableciéndose un equilibrio entre el derecho a la herencia y el derecho al respeto a la privacidad posterior al fallecimiento.

El ejercicio del poder de disposición no puede suponer un perjuicio económico para el prestador de servicios, mientras que por otro lado este no puede limitar o menoscabar la ejecución del encargo, que debe ser realizado conforme la voluntad del titular de los bienes y en el marco de la legalidad. En definitiva se trata de conciliar intereses contrarios, pero no necesariamente antagónicos.

\section{BIBLIOGRAFÍA}

Albaladejo García, Manuel, 1990: “Sección undécima. De los albaceas o testamentarios”, en Comentario al Código Civil español, tomo XII, Vol 2: Artículos 892 a 911 del Código Civil, $2^{a}$ edición. Disponible en http://www.vlex.com/vid/228705.[Fecha de consulta: 20.05.2018]. Álvarez Lata, Natalia, 2002: "Algunas cuestiones sobre el contenido atípico del testamento", Anuario da Facultade de Dereito da Universidade da Coruña, No 6, pp. 113-132. Disponible en https://core.ac.uk/download/pdf/61894038.pdf. [Fecha de consulta 20. 11. 2018].

Conway, H.; Grattan, S., 2017: “The 'New' New Property: Dealing with Digital Assets on Death", en Conway, H., Hickey, R. (Eds.), Modern Studies in Property Law, Volume 9, 1st ed., Hart Publishing, Oxford.

Domínguez Merino, Óscar, 2016: “¿Cómo influye el testamento digital en el SEO?”, en Oliva León, Ricardo y Valero Barceló, Sonsoles (coord.), Testamento ¿Digital?, edición especial, España, Colección Desafíos legales, Juristas con futuro.

Díez-Picazo, Luis; Gullón Ballesteros, Antonio, 2006: Sistema de Derecho Civil Volumen VI Derecho de Familia, España, Editorial Tecnos. 
Faus, Manuel, 2004: “Sección: Sucesión testada: La legítima y la mejora en derecho común”, en Breviario civil. 5: Las sucesiones, España, VLEX-226990.

García Herrera, V., 2017: "La disposición sucesoria del patrimonio digital", en Actualidad Civil, $\mathrm{N}^{\circ} 7-8$.

INER GANDÍA, Judith, 2016: “El testamento digital sí existe y ya ha llegado”, en Oliva León, Ricardo y Valero Barceló, Sonsoles (coord.), Testamento ¿Digital?, edición especial, España, Colección Desafíos legales, Juristas con futuro.

GonzÁlez Granado, Javier, 2016: “Sólo se muere una vez: ¿Herencia digital?”, Oliva León, Ricardo y Valero Barceló, Sonsoles (coord.), Testamento ¿Digital?, edición especial, España, Colección Desafíos legales, Juristas con futuro.

Lacruz Berdejo, José Luis y Sancho Rebullida, Francisco de Asis, 1988: Derecho de Sucesiones, Madrid, Librería Bosch.

LeE, Jeehyeon (Jenny), 2015: "Death and Live Feeds: Privacy Protection in Fiduciary Access to Digital Assets", Columbia Business Law Review, No 654.

Llopis Benlloch, José Carmelo, 2016: "Con la muerte digital no se juega: el testamento online no existe”, en Oliva León, Ricardo y Valero Barceló, Sonsoles (coord.), Testamento ¿Digital?, edición especial, España, Colección Desafíos legales, Juristas con futuro.

Lluch Cerdá, Carlos, 2016: "El reto de una muerte digital... digna”, en Oliva León, Ricardo y Valero Barceló, Sonsoles (coord.), Testamento ¿ Digital?, edición especial, España, Colección Desafíos legales, Juristas con futuro.

MárqueZ Villén, Francisco José, 2016: “Testamento digital Nuevas tecnologías y Derecho”, publicaciones de In Diem abogados. Disponible en https://www.in-diem.com/.../CUADERNOSIN-DIEM-Abogados-Testamento-Digital-2p..., [Fecha de consulta 20.11. 2018].

National Conference of Commissioners on Uniform State Laws, 2015: Revised Uniform Fiduciary Access to Digital Assets Act (con notas y comentarios). Disponible en https://www.uniformlaws.org/HigherLogic/System/DownloadDocumentFile. ashx? DocumentFileKey=112ab648-b257-97f2-48c2-61 fe109a0b33\&forceDialog =0 [Fecha de consulta 12. 05. 2018].

Salamanca Rodríguez, Francisco Rosales de 2016: “Testamento digital”, en Oliva León, Ricardo y Valero Barceló, Sonsoles (coord.), Testamento ¿Digital?, edición especial, España, Colección Desafíos legales, Juristas con futuro.

SAntos Morón, María José, 2018: "La denominada "herencia digital": ¿necesidad de regulación? Estudio de derecho español y comparado”, en Cuadernos de Derecho Transnacional, Vol. 10, $\mathrm{N}^{\circ} 1$, marzo.

Normas jurídicas citadas:

Reglamento (UE) 2016/679 del Parlamento Europeo y el Consejo, de 27 de abril de 2016, relativo a la protección de las personas físicas en lo que respecta al tratamiento de sus datos personales y a la libre circulación de estos datos (Reglamento General de Protección de Datos).

ReVised UNiform Fiduciary Access to Digital Assets Act (2015), redactado por the National Conference of Commissioners on Uniform State Laws y aprobado en la Conferencia Anual, Williamsburg, Virginia July 10-July 16, 2015. Disponible en https://www.uniformlaws. org/HigherLogic/System/DownloadDocumentFile.ashx? DocumentFileKey=112ab648-b25797f2-48c2-61fe109a0b33\&forceDialog $=0$ [Fecha de consulta 12. 05. 2018].

Real Decreto de 24 de julio de 1889 por el que se publica el Código Civil, publicado en la Gaceta de Madrid, No 206, de 25 de julio de 1889. 
LEY N 2016-1321 de 7 de octubre de 2016, por una República Digital, publicado en el Jornal Oficial de la República Francesa el 8 de octubre de 2016.

LEY 10/2017, de 27 de junio, De las voluntades digitales y de modificación de los libros segundo y cuarto del Código Civil de Cataluña, Boletín Oficial del Estado, No 173, viernes 21 de julio de 2017.

Ley Orgánica 3/2018, de 5 de diciembre, de Protección de Datos Personales y garantía de los derechos digitales, Boletín Oficial del Estado N² 294, 6 de diciembre de 2018.

LEY $\mathrm{N}^{\circ} 12.965$, de 23 de abril de 2014, establece los principios, garantías, derechos y deberes para el uso de Internet en Brasil, Congreso Nacional de la República Federativa de Brasil.

LEY N $\mathrm{N}^{\circ}$ 13.709, de 14 de agosto de 2018, sobre la protección de datos personales, Congreso Nacional de la República Federativa de Brasil.

Ley Federal de Protección de Datos Personales en posesión de los Particulares de Los Estados Unidos Mexicanos, Congreso General de los Estados Unidos Mexicanos, Diario Oficial de la Federación, 5 de julio de 2010.

Proyecto de Ley Orgánica de Protección de Datos de Carácter Personal, 21 de noviembre de 2017, en Proyecto de Ley de 24 de noviembre de 2017, No 13-1 (21/000013).

Jurisprudencia citada:

Agencia Española de Protección de Dato, Procedimiento No: TD/01859/2016, Recurso de Reposición No RR/00428/2017.

Tribunal Constitucional español, sentencia de 17 de enero de 2019 sobre el recurso de inconstitucionalidad $\mathrm{N}^{\circ}$ 4751-2017, ponente magistrado Andrés Ollero, con el voto particular discrepante de la Magistrada doña Encarnación Roca Trías. Disponible en https://www. iustel.com/diario_del_derecho/noticia.asp? ref_iustel=1184958\&utm_source=DD\&utm_ medium =email\&utm_campaign=30/1/2019 [Fecha de consulta 30.01.2019]. 
